\title{
Film Dokumenter Budaya Betawi Ondel-Ondel di Negeri Silancang Kuning Berdasarkan Sinematografi Teknik Pengambilan Gambar
}

\author{
Muhammad Daru Kardewa ${ }^{1)}$, Arta Uly Siahaan, M. Pd ${ }^{2)}$ \\ 1) Jurusan Teknik Informatika, Politeknik Negeri Batam, Batam 29461, email: \\ batam.eyedesign@gmail.com \\ 2) Jurusan Teknik Informatika, Politeknik Negeri Batam, Batam 29461, email: \\ artauly@polibatam.ac.id
}

\begin{abstract}
Abstrak
Budaya Betawi semakin terpinggirkan karena Kota Jakarta mengalami urbanisasi berlebihan sehingga terjadi persaingan di dunia kerja dan banyak masyarakat Betawi yang pergi meninggalkan Kota kelahirannya menuju Kota yang banyak memiliki lapangan perkerjaan seperti Kota Batam. Kota Batam merupakan salah satu Kota dengan tingkat pertumbuhan ekonomi yang tinggi sehingga masyarakat Betawi banyak yang memilih ke Kota Batam untuk mendapatkan perkerjaan. Masyarakat di Batam kebanyakan tidak mengenal Budaya Betawi karena warga Betawi yang tinggal di Batam tidak mengenalkan kebudayaan Betawi. Penelitian ini bertujuan untuk menghasilkan sebuah film dokumenter untuk memberikan informasi yang lebih jelas untuk mengenalkan Budaya Betawi kepada masyarakat Betawi asli dan masyarakat Kota Batam. Film ini juga memberikan informasi sinematografi teknik pengambilan gambar yang digunakan pada film dokumenter. Film dikemas menjadi CD yang akan diberikan kepada ketua forum Betawi untuk dipertontonkan bersama masyarakat Betawi dan Masyarakat Kota Batam. Setelah diuji, film ini dapat diterima dengan baik dan berhasil memberikan informasi mengenai Budaya Betawi terhadap masyarakat non Betawi dan Betawi yang ada di Kota Batam.
\end{abstract}

Kata Kunci: Budaya Betawi, Film Dokumenter, Sinematografi Teknik Pengambilan Gambar

\begin{abstract}
The Betawi culture is increasingly marginalized because Jakarta is experiencing rapid urbanization, so that the onset of competition in the world of work and many people were going to leave his hometown and working to other city for instance Batam city. Batam city is one of the cities with high economic growth rates so that Betawi people come to Batam for getting job. Based on an initial survey, it shows that Betawi culture is not really famous among the citizens in Batam. This research aims to make a documentary film to provide information that is more apparent in dissemination to the public of the Betawi and Batam City Community. The film is a cinematographic technique which provides information used in the filming of documentaries. The film is packed into a $\mathrm{CD}$ that will be submitted to the chairman of the Betawi forum in Batam and society Betawi of Batam City Community. Based on the try out, this film is well received and successfully gave the information about the culture of the non-Betawi and Betawi that exist in Batam city.
\end{abstract}

Keywords: Betawi Culture, Documentary Film, Cinematographic Camera Angle Technique . 


\section{PENDAHULUAN}

Suku Betawi adalah suku yang berasal dari hasil perkawinan antar etnis dan bangsa di masa lalu. Kelompok etnis ini lahir dari perpaduan kelompok etnis yang lebih dahulu tinggal di Jakarta dan tergolong budaya campuran. Budaya Betawi semakin terpinggirkan karena Kota Jakarta mengalami urbanisasi berlebihan. Semakin besar tingkat urbanisasi yang terjadi di Jakarta maka kebudayaan Betawi akan menurun eksistensinya [1]. Dengan adanya persaingan yang tinggi untuk mendapatkan pekerjaan banyak masyarakat Betawi yang pergi meninggalkan Kota kelahirannya menuju Kota yang banyak memiliki lapangan perkerjaan seperti Kota Batam.

Kota Batam merupakan salah satu Kota dengan tingkat pertumbuhan ekonomi yang tinggi sehingga masyarakat Betawi banyak yang memilih ke Kota Batam untuk mendapatkan perkerjaan. Masyarakat di Batam kebanyakan tidak mengenal Budaya Betawi karena warga Betawi yang tinggal di Batam tidak mengenalkan kebudayaan Betawi. Suku Betawi asli yang berdarah Betawi kebanyakan tidak ingin meninggalkan kampung halamannya tetapi dari sebagian yang berdarah Betawi ada juga yang ingin meninggalkan kampung halamannya karena sebuah alasan. Lapangan kerja yang tersedia dan kebutuhan ekonomi semakin meningkat adalah salah satu alasan masyarakat Betawi meninggalkan Kota Jakarta.

Data-data yang dikumpulkan mengenai Budaya Betawi dan kehidupan warga Betawi yang tinggal di Batam akan dijadikan satu dalam film dokumenter. Film dokumenter adalah sebuah rekaman peristiwa yang diambil dari kejadian yang nyata atau sungguhsungguh terjadi. Film dokumenter sebagai salah satu jenis film yang merupakan sebuah laporan aktual yang kreatif berdasarkan kenyataan. [2] Dokumentasi diperoleh melalui dokumen-dokumen dari hal-hal yang diteliti.

Dalam membuat film pendek atau film dokumenter yang baik harus lebih memperhatikan teknik sinematografi khususnya teknik pengambilan gambar. Penulis mengambil tema tentang perantauan Betawi yang tinggal di Kota Batam dan memasukkan beberapa informasi tentang budaya Betawi. Dengan menggunakan metode sinematografi dalam teknik pengambilan gambar film dokumenter akan terlihat lebih jelas dan mudah dipahami.

\section{LANDASAN TEORI}

Penelitian sebelumnya yang berjudul "Penyampaian Pesan Moral Melalui Teknik Sinematografi dalam Film Kain Bendera" menghasilkan sebuah film yang membahas pesan moral melalui teknik sinematografi dalam film kain bendera. Fokus pembahasannya adalah angle camera yang bersifat naratif. Hasil dari penelitian juga menjelaskan teknik sinematografi angle camera [3]. Selanjutnya penelitian yang lain adalah menghasilkan sebuah film informasi wisata pantai goa pacitan yang menarik dengan menggunakan animasi [4]. Ditemukan lagi penelitian yang menghasilkan sebuah film dokumenter berjudul "Sejarah Uang Dinar dan Dirham di Indonesia" yang mana penelitian ini dijadikan sebagai arsip sejarah Indonesia [5]. Dari penelitian - penelitian diatas, penulis membuat film dokumenter yang menceritakan tentang masyarakat Betawi yang hidup merantau dan memperkenalkan Budaya Betawi yang mulai hilang berdasarkan sinematografi sudut pandang kamera (angle camera) sehingga film terlihat optimal dan baik. Maka yang menjadi tujuan penelitian ini adalah menghasilkan film dokumenter yang akan berguna sebagai media pengenalan Budaya Betawi.

Kebudayaan Betawi telah terbentuk melalui proses yang panjang, walaupun pada kenyataanya sekarang Betawi mulai terpinggirkan. Budaya Betawi memiliki ragam kesenian beserta dengan akulturasi budaya, bahasa dan manusia yang menimbulkan berbagai persepsi terhadap suku Betawi. Penduduk aslli Kota Jakarta adalah Suku Betawi. [6] Masyarakat Betawi mempunyai beberapa budaya dan seni budaya seperti, bahasa, busana atau pakaian adat, seni tari, seni pertunjukan, lagu daerah, seni bela diri, masakan khas Betawi.

Film lebih banyak dipengaruhi oleh faktor perkembangan budaya baik dari unsur pola atau kerangka pikir, ilmu pengetahuan, teknologi, keterampilan maupun perpaduan berbagai bentuk seni yang ada di dalamnya. [7] Film adalah dokumenter atau documentary adalah turunan dari bahasa Prancis dokumentaire yang berarti sebuah film atau pembicaraan yang menggambarkan suatu peristiwa yang nyata. Film dokumenter tidak pernah terlepas dari tujuan utuk memberikan informasi atau penyebaran informasi.

Sinematografi adalah kata serapan dari bahasa Inggris Cinematography yang berasal dari bahasa latin kinema. Sinematografi sebagai ilmu terapan merupakan bidang ilmu yang membahas tentang teknik menangkap gambar dan menggabung-gabungkan gambar tersebut sehingga menjadi rangkaian gambar yang dapat menyampaikan ide.

Adapun software yang digunakan dalam pembuatan film ini adalah Adobe Premiere yang merupakan salah satu software editing video yang banyak digunakan pasca produksi. Adobe After Effect adalah software editing video yang paling mempermudah pasca produksi pengeditan video. Software ini dapat digunakan dalam pengeditan animasi 2D atau 3D juga untuk pengeditan video klip. Adobe Audition adalah produk adobe yang biasanya digunakan untuk pengeditan suara. Adobe Audition digunakan untuk menghilangkan suara yang tidak diinginkan dan mengatur suara. Adobe photoshop adalah produ ado kbe photoshop yang biasa digunakan untuk mengatur, 
mengedit, dan membuat gambar. Adobe photoshop digunakan untuk mengedit sebuah gambar dan foto. Adapun software yang digunakan untuk pembuatan film dokumenter ini disajikan pada Tabel 1.

Tabel 1. Software yang digunakan dalam pembuatan film dokumenter

\begin{tabular}{|l|l|l|}
\hline No & \multicolumn{1}{|c|}{ Software } & \multicolumn{1}{c|}{ Kegunaanya } \\
\hline 1 & $\begin{array}{l}\text { Adobe } \\
\text { Premiere }\end{array}$ & $\begin{array}{l}\text { Digunakan untuk tahap } \\
\text { Pasca Produksi }\end{array}$ \\
\hline 2 & $\begin{array}{l}\text { Adobe } \\
\text { Photoshop }\end{array}$ & $\begin{array}{l}\text { Digunakan untuk meng- } \\
\text { edit gambar dan foto }\end{array}$ \\
\hline 3 & $\begin{array}{l}\text { Adobe After } \\
\text { Effect }\end{array}$ & $\begin{array}{l}\text { Digunakan untuk } \\
\text { memberikan effect pada } \\
\text { video }\end{array}$ \\
\hline 4 & $\begin{array}{l}\text { Adobe } \\
\text { Audition }\end{array}$ & $\begin{array}{l}\text { Digunakan untuk mengedit } \\
\text { file berupa Audio }\end{array}$ \\
\hline
\end{tabular}

Selanjutnya, adapun Hardware yang digunakan dalam pembuatan film dokumenter ini disajikan pada Tabel 2 .

Tabel 2. Hardware yang digunakan dalam pembuatan film dokumenter

\begin{tabular}{|l|l|l|}
\hline No & \multicolumn{1}{|c|}{ Hardware } & \multicolumn{1}{c|}{ Kegunaanya } \\
\hline 1 & $\begin{array}{l}\text { Kamera } \\
\text { Canon DSLR } \\
600 D\end{array}$ & $\begin{array}{l}\text { Digunakan untuk } \\
\text { mengambil gambar }\end{array}$ \\
\hline 2 & $\begin{array}{l}\text { Memory Card } \\
\text { Sandisk }\end{array}$ & $\begin{array}{l}\text { Digunakan untuk } \\
\text { menyimpan Gambar dan } \\
\text { Video }\end{array}$ \\
\hline 4 & Microphone & $\begin{array}{l}\text { Digunakan untuk supaya } \\
\text { saat pengambilan gambar } \\
\text { tidak bergerak }\end{array}$ \\
\hline 5 & Carara \\
\hline 6 & Komputer & $\begin{array}{l}\text { Digunakan untuk } \\
\text { memindahkan hasil foto dan } \\
\text { video kedalam computer }\end{array}$ \\
\hline
\end{tabular}

\section{METODE PENELITIAN}

Ada beberapa tahapan yang dilakukan dalam pembuatan film dokumenter ini yakni tahapan praproduksi, produksi dan pasca produksi. Pada Gambar 1 disajikan susunan proses pembuatan film.

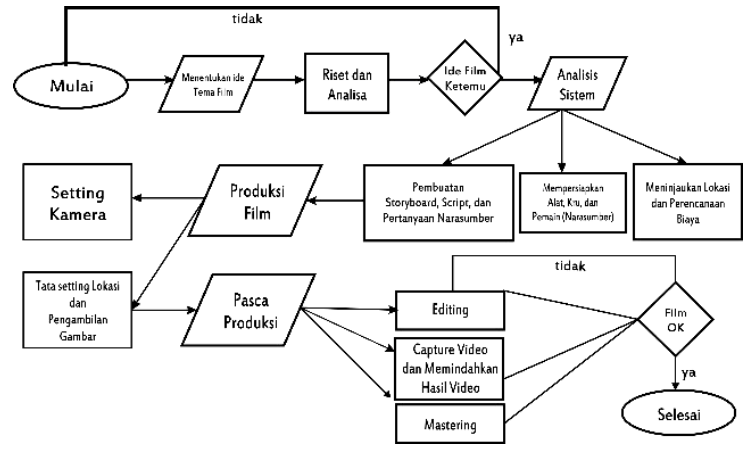

Gambar 1. Proses Pembuatan Film

\section{a. Pra Produksi}

Pra produksi merupakan tahapan kerja terpenting atau utama dalam setiap produksi film. Pra produksi yang biasa dilakukan seperti menentukan ide dan tema film, membuat sinopsis, melakukan riset, analisis sistem, identifikasi masalah dan pembuatan storyboard. Pada Tabel 3, disajikan salah satu contoh pembuatan storyboard dalam film dokumenter.

Tabel 3. Pembuatan Storyboard Dalam Film Dokumenter

\begin{tabular}{|c|c|c|c|c|}
\hline Video & $\begin{array}{l}\text { Story } \\
\text { board }\end{array}$ & Audio & $\begin{array}{c}\text { Camera } \\
\text { Angle }\end{array}$ & $\begin{array}{c}\text { F } \\
\text { ra } \\
\text { m } \\
\text { e }\end{array}$ \\
\hline $\begin{array}{l}\text { Pesawat } \\
\text { turun } \\
\text { Landas }\end{array}$ & & $\begin{array}{l}\text { Si Doel } \\
\text { Anak } \\
\text { Sekolah } \\
\text { an }\end{array}$ & $\begin{array}{l}\text { (LS) } \\
\text { Long } \\
\text { Shoot }\end{array}$ & 4 \\
\hline $\begin{array}{l}\text { Fajri } \\
\text { keluar } \\
\text { dari } \\
\text { Pesawat }\end{array}$ & & $\begin{array}{l}\text { Si Doel } \\
\text { Anak } \\
\text { Sekolah } \\
\text { an }\end{array}$ & $\begin{array}{l}\text { (MS) } \\
\text { Medium } \\
\text { Shot }\end{array}$ & 5 \\
\hline
\end{tabular}

\section{b. Produksi}

Tahapan ini merupakan tahap lanjutan dari proses pra produksi, pada tahap produksi konsep yang dibuat mengikuti sesuai tahap praproduksi yang akan dilaksanakan pada tahap ini. Adapun kegiatan yang dilakukan dalam proses produksi antara lain pengambilan gambar secara keseluruhan mulai dari awal dan akhir. Pengambilan gambar diambil sesuai storyboard yang dibuat. Pada Tabel 4 disajikan salah satu contoh pengambilan gambar sesuai dengan storyboard. 
Tabel 4. Pengambilan Gambar Sesuai Storyboard

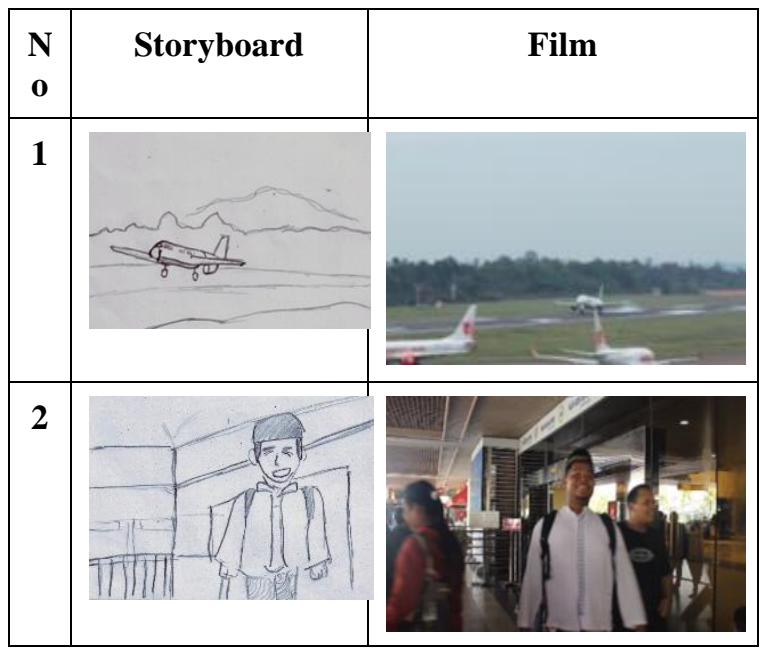

Teknik pada saat pengambilan gambar komposisi adalah hal terpenting dan bagian sederhana untuk mengatur elemen pada gambar, sehingga dapat memberikan sebuah maksud perasaan yang diinginkan.

\section{c. Pasca Produksi}

Pasca produksi merupakan tahap akhir pada pembuatan film dokumenter ini. Ketika tahap produksi selesai, tahapan selanjutnya mengirim hasil video dari memori ke komputer, melakukan editing pada hasil video yang diambil, melakukan Rendering, melakukan pengujian pada film, membuat kuisioner untuk mendapatkan hasil penelitian dan membuat poster. Proses Rendering Film disajikan pada Gambar 2.

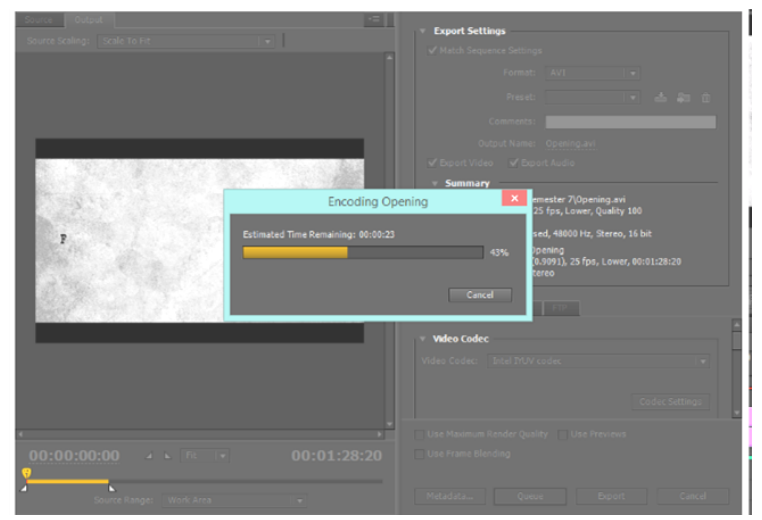

Gambar 2. Proses Rendering pada Film

\section{HASIL DAN PEMBAHASAN}

Setelah menyelesaikan tahapan Rendering, maka selanjutnya dilakukan pengujian film dengan membagikan kuesioner berisi pernyataan yang berkaitan dengan pendapat mengenai film dokumenter yang telah dibuat. Kuesioner disebarkan kepada 15 Masyarakat Betawi yang ada di Kota Batam. Masyarakat Betawi di Kota Batam berperan penting dalam pemutaran film dokumenter supaya masyarakat
Betawi di Kota Batam mengetahui Forum Silaturahmi Warga Jakarta.

Kuesioner disebarkan kepada 100 masyarakat Kota Batam untuk mengetahui tanggapan mereka mengenai film dokumenter. Masyarakat Kota Batam yang bukan asli Betawi juga berperan penting pada film dokumenter supaya orang yang bukan asli Betawi mengenal Budaya Betawi dan mengetahui adanya forum Betawi yang ada di Batam.

Kuesioner disebar menggunakan cluster sampling atau sampling area yang biasanya digunakan jika sumber data atau populasi misalnya penduduk suatu propinsi, kabupaten atau masyarakat yang menyebar di seluruh provinsi. Tahap pertama menentukan sample masingmasing kecamatan yang di Batam. Pada Tabel 5 disajikan Data kecamatan yang ada di Batam.

Tabel 5. Data Kecamatan yang ada di Batam

\begin{tabular}{|l|l|l|}
\hline No. & \multicolumn{1}{|c|}{$\begin{array}{c}\text { Nama } \\
\text { Kecamatan }\end{array}$} & $\begin{array}{c}\text { Jumlah Kuesioner } \\
\text { yang disebar }\end{array}$ \\
\hline 1 & Kec. Batu Ampar & 20 \\
\hline 2 & Kec. Bengkong & 20 \\
\hline 3 & Kec. Batam Kota & 20 \\
\hline 4 & Kec. Lubuk baja & 20 \\
\hline 5 & Kec. Batu Aji & 20 \\
\hline
\end{tabular}

Pernyataan ini dibuat harus berdasarkan Data yang dibutuhkan untuk menjadi bukti. Pada Tabel 6 Disajikan kuesioner yang disebarkan.

Tabel 6. Data Kuesioner yang Disebarkan

\begin{tabular}{|c|c|c|c|c|c|c|c|}
\hline \multirow[b]{2}{*}{$\begin{array}{l}\mathrm{N} \\
\mathrm{O}\end{array}$} & \multirow[b]{2}{*}{ Pernyataan } & \multicolumn{6}{|c|}{ Kesimpulan } \\
\hline & & $\begin{array}{c}\text { SS } \\
5\end{array}$ & $\begin{array}{l}S \\
4\end{array}$ & $\begin{array}{l}N \\
3\end{array}$ & $\begin{array}{l}\mathrm{T} \\
\mathrm{S} \\
2\end{array}$ & $\begin{array}{l}\mathrm{S} \\
\mathrm{T} \\
\mathrm{S} \\
1\end{array}$ & Total \\
\hline 1 & $\begin{array}{l}\text { Film } \\
\text { Dokumenter } \\
\text { ini } \\
\text { Penyampaia } \\
\text { nnya Jelas } \\
\text { Film ini }\end{array}$ & 50 & 38 & 10 & 2 & 0 & 130 \\
\hline 2 & $\begin{array}{l}\text { Menceritaka } \\
\mathrm{n} \\
\text { masyarakat } \\
\text { Betawiyang } \\
\text { tinggal di } \\
\text { Kota Batam }\end{array}$ & 28 & 60 & 11 & 1 & 0 & 127 \\
\hline 3 & $\begin{array}{l}\text { Film ini } \\
\text { memberikan }\end{array}$ & 24 & 62 & 14 & 0 & 0 & 138 \\
\hline
\end{tabular}




\begin{tabular}{|c|c|c|c|c|c|c|c|}
\hline & $\begin{array}{l}\text { informasi } \\
\text { Sinematogra } \\
\text { fi teknik } \\
\text { pengambilan } \\
\text { gambar }\end{array}$ & & & & & & \\
\hline 4 & $\begin{array}{l}\text { Film ini } \\
\text { layak } \\
\text { dijadikan } \\
\text { Film } \\
\text { Dokumenter } \\
\text { mengenai } \\
\text { Budaya } \\
\text { betawi }\end{array}$ & 22 & 72 & 27 & 1 & 0 & 120 \\
\hline 5 & $\begin{array}{l}\text { Film dapat } \\
\text { menambah } \\
\text { wawasan } \\
\text { tentang } \\
\text { budaya } \\
\text { betawi }\end{array}$ & 25 & 58 & 16 & 1 & 0 & 125 \\
\hline 6 & $\begin{array}{l}\text { Kualitas } \\
\text { Film Baik } \\
\text { dan Audio } \\
\text { Jelas }\end{array}$ & 24 & 49 & 27 & 0 & 0 & 113 \\
\hline 7 & $\begin{array}{l}\text { Masyarakat } \\
\text { Betawi ke } \\
\text { Batam } \\
\text { Kebanyakan } \\
\text { karena } \\
\text { ekonomi } \\
\text { sulit } \\
\text { dijakarta }\end{array}$ & 18 & 29 & 15 & $\begin{array}{l}3 \\
8\end{array}$ & 0 & 122 \\
\hline 8 & $\begin{array}{l}\text { Pesan-Pesan } \\
\text { yang } \\
\text { disampaikan } \\
\text { warga } \\
\text { Betawi } \\
\text { dapat } \\
\text { mempengar } \\
\text { uhi dalam } \\
\text { pengembang } \\
\text { an budaya } \\
\text { betawi }\end{array}$ & 14 & 68 & 15 & 2 & 1 & 115 \\
\hline 9 & $\begin{array}{l}\text { Film } \\
\text { dokumenter } \\
\text { ini } \\
\text { mengenalka } \\
\text { n forum } \\
\text { silaturahmi } \\
\text { warga } \\
\text { jakarta yang } \\
\text { ada di } \\
\text { Batam }\end{array}$ & 40 & 45 & 14 & 1 & 0 & 139 \\
\hline
\end{tabular}

Ada 9 peryataan yang diberikan dalam kuesioner. Penyelesaian akhir menggunakan skala likert yang memiliki Rumus Penyelesaian Akhir. Rumus yang digunakan antara lain sebagai berikut :

Total Skor / Y (Jumlah Audiens x Point SS(5)) x 100. Sebelum menyelesaikan terlebih dahulu harus mengetahui interval dan interprestasi persen. Pada Tabel. 7 disajikan mengenai kriteria interprestasi skornya berdasarkan interval.

Tabel 7. Data Kuesioner Tanggapan Audiens

\begin{tabular}{|c|c|l|}
\hline No & \multicolumn{1}{|c|}{ Angka } & \multicolumn{1}{c|}{ Keterangan } \\
\hline 1 & Angka $0 \%-19,99 \%$ & $\begin{array}{l}\text { Sangat Tidak } \\
\text { Setuju }\end{array}$ \\
\hline 2 & Angka $20 \%-39,99 \%$ & Tidak Setuju \\
\hline 3 & Angka $40 \%-59,99 \%$ & Netral \\
\hline 4 & Angka $60 \%-79,99 \%$ & Setuju \\
\hline 5 & Angka $80 \%-100 \%$ & Sangat Setuju \\
\hline
\end{tabular}

Setelah mengetahui nilai kriteria interprestasi skornya berdasarkan interval. Menghitung Penyelesaian akhir menggunakan rumus. Tabel 8 menunjukkan hasil penyelesaian akhir tanggapan audiens menggunakan skala likert.

Tabel 8. Hasil Penyelesaian Akhir Tanggapan Audiens Menggunakan Skala Likert

\begin{tabular}{|c|c|c|c|}
\hline No & Pernyataan & $\begin{array}{c}\text { Rumus } \\
\text { Total } \\
\text { Skor / Y } \\
\text { x } 100\end{array}$ & $\begin{array}{c}\text { Keterangan } \\
\text { Interprestasi } \\
\text { Skor }\end{array}$ \\
\hline 1 & $\begin{array}{l}\text { Film } \\
\text { Dokumenter ini } \\
\text { Penyampaiannya } \\
\text { Jelas mengenai } \\
\text { informasi dan } \\
\text { Budaya Betawi }\end{array}$ & $\begin{array}{c}436 / 575 \\
\times 100= \\
75,8 \%\end{array}$ & Setuju \\
\hline 2 & $\begin{array}{l}\text { Film } \\
\text { Dokumenter ini } \\
\text { Penyampaiannya } \\
\text { Jelas mengenai } \\
\text { informasi dan } \\
\text { Budaya Betawi }\end{array}$ & $\begin{array}{c}415 / 575 \\
\times 100= \\
72,1 \%\end{array}$ & Setuju \\
\hline 3 & $\begin{array}{l}\text { Film ini dapat } \\
\text { memberikan } \\
\text { informasi tentang } \\
\text { teknik } \\
\text { pengambilan } \\
\text { gambar pada } \\
\text { pembuatan film } \\
\text { dengan jelas }\end{array}$ & $\begin{array}{c}410 \\
1575 \mathrm{x} \\
100= \\
71,3 \%\end{array}$ & Setuju \\
\hline
\end{tabular}




\begin{tabular}{|c|c|c|c|}
\hline 4 & $\begin{array}{l}\text { Film ini layak } \\
\text { dijadikan film } \\
\text { dokumenter } \\
\text { mengenai } \\
\text { Budaya Betawi }\end{array}$ & $\begin{array}{c}481 \\
1575 \mathrm{x} \\
100= \\
83,6 \%\end{array}$ & $\begin{array}{l}\text { Sangat } \\
\text { Setuju }\end{array}$ \\
\hline 5 & $\begin{array}{l}\text { Film ini dapat } \\
\text { menambah } \\
\text { wawasan tentang } \\
\text { Budaya Betawi }\end{array}$ & $\begin{array}{c}407 / 575 \\
\times 100= \\
70,7 \%\end{array}$ & Setuju \\
\hline 6 & $\begin{array}{l}\text { Kualitas film } \\
\text { Baik dan Audio } \\
\text { Jelas. }\end{array}$ & $\begin{array}{c}397 / 575 \\
\times 100= \\
69 \%\end{array}$ & Setuju \\
\hline 7 & $\begin{array}{l}\text { Masyarakat } \\
\text { Betawi ke Batam } \\
\text { kebanyakan } \\
\text { karena ekonomi } \\
\text { sulit di Jakarta. }\end{array}$ & $\begin{array}{c}327 / 575 \\
\times 100= \\
56,8 \%\end{array}$ & Netral \\
\hline 8 & $\begin{array}{l}\text { Pesan-pesan } \\
\text { yang } \\
\text { disampaikan } \\
\text { Warga Betawi } \\
\text { dapat } \\
\text { mempengaruhi } \\
\text { dalam } \\
\text { pengembangan } \\
\text { Budaya Betawi. }\end{array}$ & $\begin{array}{c}391 / 575 \\
\times 100= \\
68 \%\end{array}$ & Setuju \\
\hline 9 & $\begin{array}{l}\text { Film dokumenter } \\
\text { ini mengenalkan } \\
\text { forum } \\
\text { silaturahmi } \\
\text { warga jakarta } \\
\text { yang ada di } \\
\text { Batam }\end{array}$ & $\begin{array}{c}424 / 575 \\
\times 100= \\
73,7 \%\end{array}$ & Setuju \\
\hline
\end{tabular}

Responden yang menyatakan sangat setuju penyampaiannya mengenai Budaya Betawi sebesar $75,8 \%$ dan film ini memberikan informasi kepada masyarakat Betawi yang tinggal diKota Batam sebesar 72,1\%. Hasil kuesioner membuktikan bahwa mayarakat Betawi dan Masyarakat Kota Batam sangat setuju film dokumenter ondel-ondel di negeri si lancang kuning layak dijadikan film budaya Betawi sebesar 83,6\% dari kuesioner yang disebarkan film ini membuktikan bahwa $71.3 \%$ Masyarakat Kota Batam dan Betawi mengenal teknik pengambilan gambar dan film ini memiliki kualitas film baik dan audio baik. sebesar 69\%. Film ini juga dapat menambahkan wawasan tentang budaya betawi yang jelas, berdasarkan hasil kuesioner yang disebar sebesar $70,7 \%$. Film ini juga membuktikan bahwa Masyarakat betawi kebanyakan datang ke Batam karena sulitnya ekonomi sebesar $56,8 \%$ dan film ini berhasil mengenalkan tentang Forum Betawi sebesar 73,7\%, film ini juga berhasil memberikan pesan - pesan yang dapat mempengaruhi masyarakat Betawi dalam pengembangan sebesar $73,7 \%$.
Maka berdasarkan data yang sudah diperoleh, dapat disimpulkan bahwa Film Ondel - Ondel di Negeri si Lancang kuning membuktikan bahwa mayarakat Betawi dan Masyarakat Kota Batam sangat setuju film dokumenter ondel-ondel di negeri si lancang kuning dan layak dijadikan film budaya Betawi karena terdapat informasi mengenai Betawi, kehidupan dan perkumpulan forum Betawi yang ada di Batam.

\section{KESIMPULAN SARAN}

\section{a. Kesimpulan}

Berdasarkan implementasi dan pengujian pada film dokumenter, maka kesimpulan yang didapat adalah telah berhasil dalam menghasilkan sebuah film dokumenter "Ondel-Ondel di Negeri si Lancang Kuning" berdasarkan sinematografi teknik pengambilan gambar dan berhasil sebagai media informasi dalam mengenalkan kebudayaan Betawi juga memperkenalkan forum betawi yang ada di Kota Batam. Dari hasil parameter diatas penilaian kepada masyarakat didapat nilai $83,6 \%$ yang menyatakan masyarakat setuju bahwa film dokumenter ini layak dijadikan film documenter mengenai Betawi dan 73,7 $\%$ masyarakat setuju film berhasil memperkenalkan forum Betawi yang ada di Kota Batam.

\section{b. Saran}

a. Film dokumenter lebih dikembangkan dalam mengenalkan Budaya Betawi seperti menambahkan rumah adat, senjata khas Betawi, palang pintu, jenis musik, dll.

b. Dalam pembuatan film dokumenter supaya menjadi lebih baik seharusnya dibantu dengan dua atau lebih kameraman, supaya mendapatkan banyak sudut pengambilan gambar.

c. Pencahayaan pada film lebih diperhatikan seperti menggunakan Alat bantu dalam cahaya.

d. Dalam pembuatan film dokumenter yang harus diperhatikan adalah pengambilan gambar harus dengan kenyataan (fakta).

\section{DAFTAR PUSTAKA}

[1] Moechtar, M.S., Sarwadana, S.M., Semarajaya, C.G.A., 2012, identifikasi pola pemukiman Tradisional kampung Budaya Betawi setu Babakan, Kelurahan Srengseng Sawah, Kecamatan Jagakarsa, Kota Administrasi Jakarta Selatan, Provinsi DKI Jakarta, Agroekoteknologi, Fakultas Pertanian Universitas Udayana, Bali.

[2] Utami, Citra Dewi, 2010, Film Dokumenter Sebagai Media Pelestari Tradisi, Jurusan Televisi Fakultas Seni Rupa dan Desain ISI, Surakarta. 
[3] Sidik, M.N., 2012, Penyampaian Pesan Moral melalui Teknik Sinematografi dalam film "Kain Bendera", Skripsi, Fakultas Dakwah dan Komunikasi, UIN Sunan KaliJaga, Yogyakarta.

[4] Ludiro, Muhammad, 2011, Pembuatan Film Dokumenter Wisata Pantai dan Goa Di Pacitan Jawa Timur, Skripsi, Fakultas Manajemen Informatika dan Komputer, AMIKOM, Yogyakarta.

[5] Rakhmawati, Erlnda, (2012), Pembuatan Film Dokumenter Sejarah Uang Dinar dan Dirham di Indonesia, Skripsi, Fakultas Manajemen Informatika dan Komputer, AMIKOM, Yogyakarta.

[6] Yanuarizkhy, Ika, 2013, Partisipasi Masyarakat pada pelestarian Budaya Betawi di perkampungan setu bebakan, Skripsi, Universitas pendidikan Indonesia, Jakarta.

[7] Miyarso, Estu, 2011, Peran Penting Sinematografi Dalam Pendidikan Pada Era Teknologi Informasi \& Komunikasi, Majalah Pendidikan, Yogyakarta 